\title{
Research on the Job Burnout of Teachers in the Perspective of Emotional Labor Theory \\ Dong Can
}

\author{
Wu Han University of Technology, Wu Han, China
}

\author{
Keywords: Preschool Teams; Emotional Labor; Job Burnout; Social Support
}

\begin{abstract}
Child abuse is frequent and kindergarten teachers have become a hot topic of social concern. After the hot spot occurred, people criticized the responsible person while ignoring the analysis of the nature of the event. This article first combed the related studies of emotional labor theory, job burnout and social support. After careful comparison, three scales were selected: emotional labor scale, MBI job burnout scale and social support evaluation scale. The research concluded that the surface play in the three dimensions of emotional labor is positively related to job burnout and the deep play and natural behavior are negatively related to job burnout. Social support plays a moderating role in emotional labor and job burnout.
\end{abstract}

\section{Introduction}

From the perspective of emotional labor theory, this paper studies the work burnout phenomenon of kindergarten teachers, which tests the influence of surface play, deep play and natural behavior of emotional labor on the emotional failure, dehumanization and personal achievement of job burnout. This paper takes social support as intermediary variable to examine the adjustment effect of emotional labor to job burnout and carries on the empirical analysis.

The development status of early childhood education is not optimistic, and child abuse incidents emerge one after another, and it has frequently become a social hot spot. The tendency is to criticize and punish the moral of the park and teachers involved, but people ignore the analysis of the teaching staff from the perspective of management profession. The kindergarten teacher belongs to the labor group with high-emotional. The high degree of job burnout directly affects the state of work, and has a bad impact on the education of kindergarten children.

\section{Literature Review}

In 1974, the American scholar Freudenberger proposed the concept of "job burnout" in the process of studying occupational stress in the field of mental health. This is the first time that job burnout has been proposed by scholars as a professional concept. He believes that the reason for job burnout is that the practitioner's great expectation of professional mailing and the status quo is not met. In addition, the pressure that is not easily relieved eventually shows three manifestations: emotional exhaustion, dehumanization, and reduced personal achievement[1]. In 1986, Maslach believes that job burnout is a situation in which people are serving customers, and the service staff shows emotional exhaustion, dehumanization (self-depersonalization) and reduced personal achievement[2].

In 1979, Hochschlid first proposed the concept of emotional labor in his study. He believes that emotional labor is used to explain the attractive facial expressions and physical displays produced by emotional control. Performance under the influence of emotional reality norms and broader cultural rules, including perceptual rules and display rules [3]. In 1996 Morris proposed to define emotional labor theory as "the emotional effort expressed by employees in accordance with organizational requirements when interacting with customers"[4]. It emphasizes the interpersonal mode of emotion, that is, the emotional consistency between personal feelings and organizational requirements. In 2003, Diefendorff and Gosserand, based on Hochschlid, extended the three-dimensional theory of emotional labor to surface play, deep play, and natural behavior, and compiled the "Emotional Labor Questionnaire"[5]. The surface 
plays 7 questions, deep plays 4 questions, and natural behavior 3 questions. It has good reliability and validity.

In 1976, scholar Cobb proposed that social support was defined as three dimensions, namely emotional support, respect support, and membership [6]. Emotional support refers to individuals believing that they have received care and love from others. Respect support refers to individuals believing that they are respected by others. Membership refers to individuals belonging to an organization or group. In 1988 House et al. proposed three sub-concepts with social relations as their general concept: social integration, social networks, and social support[7]. However, this approach has caused conceptual confusion to some extent.

\section{Research Design}

\subsection{Assumptions.}

From the review above, we can know that the three dimensions of emotional labor play different related roles in the three dimensions of job burnout. The following assumptions are made:

H1: Surface play has a significant positive correlation with job burnout at work.

H2: Deep play has a significant negative correlation with job burnout at work.

H3: Natural behavior has a significant negative correlation with job burnout at work.

H4: Social regulation has a regulatory effect between emotional labor and job burnout.

\subsection{Model.}

The model includes two research variables: emotional labor and job burnout. Combining the multidimensional characteristics of emotional labor and job burnout, emotional labor is three-dimensional: surface play, deep play, and natural behavior. Job burnout is emotional failure, dehumanization, and personal achievement in three dimensions. Social support factors play a moderating role between emotional labor and job burnout.
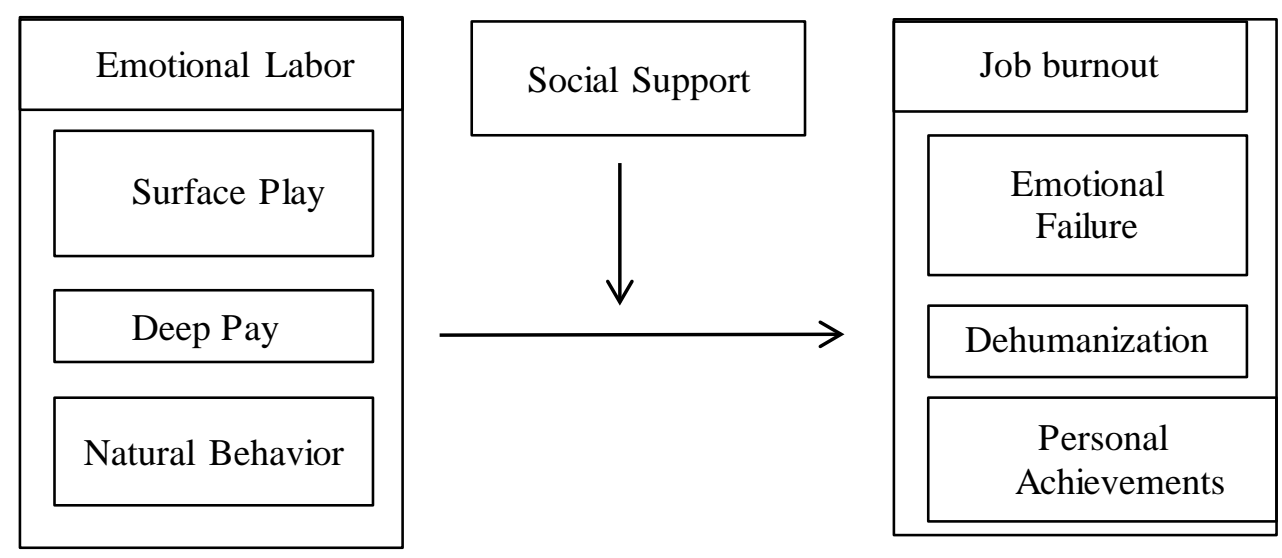

Fig. 1 Theoretical model

\section{Data Analysis}

The subject of this study is the child teacher, using the questionnaire star to collect data, a total of 170 questionnaires were collected, effective questionnaire 152 recovery rate of $89.4 \%$. This questionnaire received a total of 152 effective questionnaires. From a gender perspective, preschool teachers are mainly women, accounting for up to $85 \%$; from an age point of view, the younger age structure of early childhood teachers is obvious. Teachers under the age of 30 account for more than $70 \%$, and teachers over the age of 40 account for less than $5 \%$. From the point of view of teaching age, the distribution of young and old teachers is reasonable. 
Table 1 shows some descriptive statistical characteristics of the main variables in this study, such as correlation coefficient, mean, standard deviation, etc. The correlation between the influences of each dimension of emotional labor on each dimension of job burnout is verified.

Table 1 Statistical description of the variables

\begin{tabular}{|c|c|c|c|c|c|c|c|c|c|}
\hline Sum & Ave & SD & $\begin{array}{c}\text { Surface } \\
\text { Play }\end{array}$ & $\begin{array}{c}\text { Deep } \\
\text { Play }\end{array}$ & $\begin{array}{c}\text { Natural } \\
\text { Behavior }\end{array}$ & $\begin{array}{c}\text { Emotional } \\
\text { Failure }\end{array}$ & Dehumanization & $\begin{array}{c}\text { Personal } \\
\text { Achievement }\end{array}$ & $\begin{array}{c}\text { Social } \\
\text { Support }\end{array}$ \\
\hline Surface Play & 2.42 & 0.923 & 1 & & & & & & \\
\hline Deep Play & 3.58 & 1.107 & -0.627 & 1 & & & & & \\
\hline Natural Behavior & 3.32 & 1.322 & -0.710 & 0.619 & 1 & & & & \\
\hline Emotional Failure & 2.39 & 0.963 & 0.718 & -0.899 & -0.723 & 1 & & & \\
\hline Dehumanization & 2.39 & 0.493 & 0.711 & -0.870 & -0.718 & 0.940 & 1 & & \\
\hline $\begin{array}{c}\text { Personal } \\
\text { Achievement }\end{array}$ & 3.44 & 1.036 & -0.771 & 0.752 & 0.794 & -0.0838 & -0.814 & 1 & \\
\hline Social Support & 2.33 & 0.624 & 0.047 & 0.171 & 0.058 & -0.174 & -0.147 & -0.051 & 1 \\
\hline
\end{tabular}

Combined with the above results, it can be seen that:

H1: Surface play has a significant positive correlation with job burnout.

H2: Deep play has a significant negative correlation with job burnout.

H3: Natural behavior has a significant negative correlation with job burnout generated at work.

The adjustment between emotional labor and job burnout is tested by simple slope. The mean of social support plus a standard deviation gets a high social support level group and the average of social support minus a standard deviation gets a low social support level group. The relationship between emotional labor and job burnout was investigated by regression grouping.

Under the adjustment of social support, the relationship between surface play and job burnout is positively regulated.

Under the adjustment of social support, there is no significant adjustment relationship between deep play and job burnout.

Under the adjustment of social support, the relationship between natural behavior and job burnout is negatively regulated.

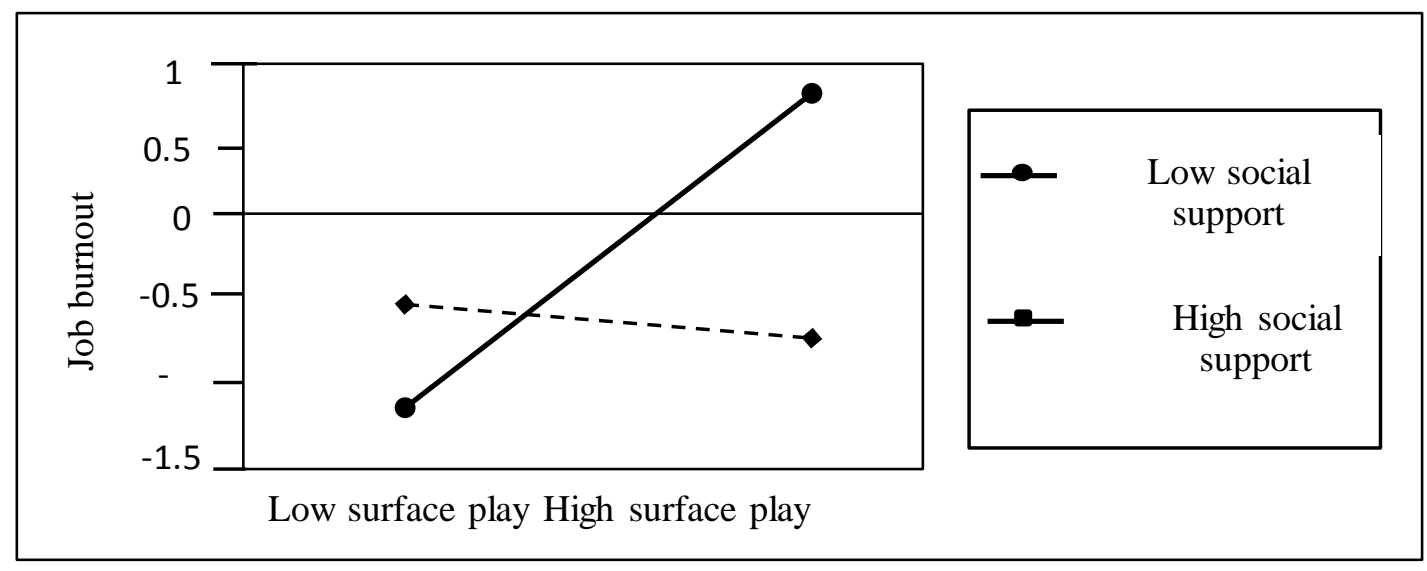

Fig. 2 Regulatory effects of surface play and job burnout

\section{Conclusions and Shortcomings}

This paper took kindergarten teacher as the research object, constructed a mediated model, and from the perspective of emotional labor theory, researched the relationship between the three dimensions of emotional labor: surface play, deep play, natural behavior and job burnout is discussed and whether or not social support is received to regulate the impact of the variable. The study is helpful to analyze the relationship between surface play, deep play, natural behavior and job burnout. Examine the regulatory role of social support. It is concluded that: 
In the sample data, the teacher's job burnout status is in the middle level, emotional exhaustion and dehumanization level are in the lower middle level, but the personal achievement reduction score is the highest and should be paid attention.

The three variables of gender, age and teaching age had no significant effect on job burnout.

Surface play plays a significant positive correlation to job burnout in emotional labor. Deep play has a significant negative correlation with job burnout; Natural behavior has a significant negative correlation with job burnout.

Social support acts as a regulator between emotional labor and job burnout. Under the adjustment of social support, the relationship between surface play and job burnout is positive, and there is no significant adjustment between deep play and job burnout.

The relationship between natural behavior and job burnout is negatively regulated.

This study uses the questionnaire method, although the questionnaire method can be collected and collated in a wider range of time and regions, but the information obtained is relatively fixed, and there is no vivid feedback from the respondents. There are two perspectives for empirical research on a certain population. One is cross-sectional research, that is, research on the collection of relevant data by the studied population at a certain time. Vertical research refers to the tracking of a group of people for a long period of time, and the characteristics of the population studied at different stages of development can be obtained.

\section{Acknowledgment}

The study supported by “the National Social Science Foundation Project (17BG209), Hubei Science and Technology Department Soft Science Research Project (2018ADC020), Central University Funds for Basic Scientific Research (2018VI001)”.

\section{References}

[1] Freudenberger, Herbert J. "Staff Burn - Out" Journal of Social issues, 2010, pp. 159-165.

[2] Solano, Madrigal, and D. Myleen. "4 Maslach C.Jackson S. The measurement of experienced burnout" Journal of Occupational Behaviour, 1981, pp. 99-113.Medicina Legal De Costa Rica.

[3] Hochschild, Arlie Russell. "Emotion Work, Feeling Rules, and Social Structure" American Journal of Sociology, 1979, pp. 551-575.

[4] Ashforth, Blake E., and R. H. Humphrey. "Emotional Labor in Service Roles: The Influence of Identity" Academy of Management Review, 18.1,1993, pp. 88-115.

[5] Diefendorff, James M., and R. H. Gosserand. "Understanding the emotional labor process: a control theory perspective" Journal of Organizational Behavior, 2003, pp.945-959.

[6] Cobb, Sidney. "Social support as a moderator of life stress" Psychosomatic Medicine, 1976, pp.300-314.

[7] House, J. S., D. Umberson, and K. R. Landis. "Structures and Processes of Social Support" Annual Review of Sociology, 1988, pp.293-318. 